\title{
Dire prognostication with the death of the Health Accord
}

W

ith the 10-year health care funding agreement between the federal, provincial and territorial authorities expiring at the end of March, health authorities and public health advocates are expressing concern about the erosion of national, universal health care as we know it.

The 2004 Health Accord was a formal agreement between the federal and provincial governments, guaranteeing the latter an annual 6\% increase in federal health care funding and setting various targets for health system improvements. The Health Accord, the first agreement of its kind in Canada, was a key recommendation in the 2002 Romanow Commission report and a response to years of declining federal funding and leadership.

When the federal government decided in 2011 not to renew the accord, thenfinance minister Jim Flaherty explained his government wanted a simplified funding plan that would avoid the long, back-and-forth negotiations required to finalize the Health Accord.

"We want to put the issue of funding behind us to allow us all to focus on the real issue - how to improve the system," he told media.

The Conservative government's new formula will see the Canada Health Transfer increase in tandem with the gross domestic product, with a guaranteed floor of 3\% per year. That means the provinces and territories will receive $\$ 36$ billion less over the next 10 years (based on an annual economic growth projection of 4\%), according to research by the Council of the Federation, a body comprising Canada's 13 premiers.

The federal government is balancing its budget "on the backs of the provinces," said Adrienne Silnicki, the health care campaigner for the Council of Canadians, a social justice advocacy group. "It's forcing them to de-list needed services and invite in more private health care providers."

Other advocates, including Colin Busby, a senior policy analyst at $\mathrm{CD}$

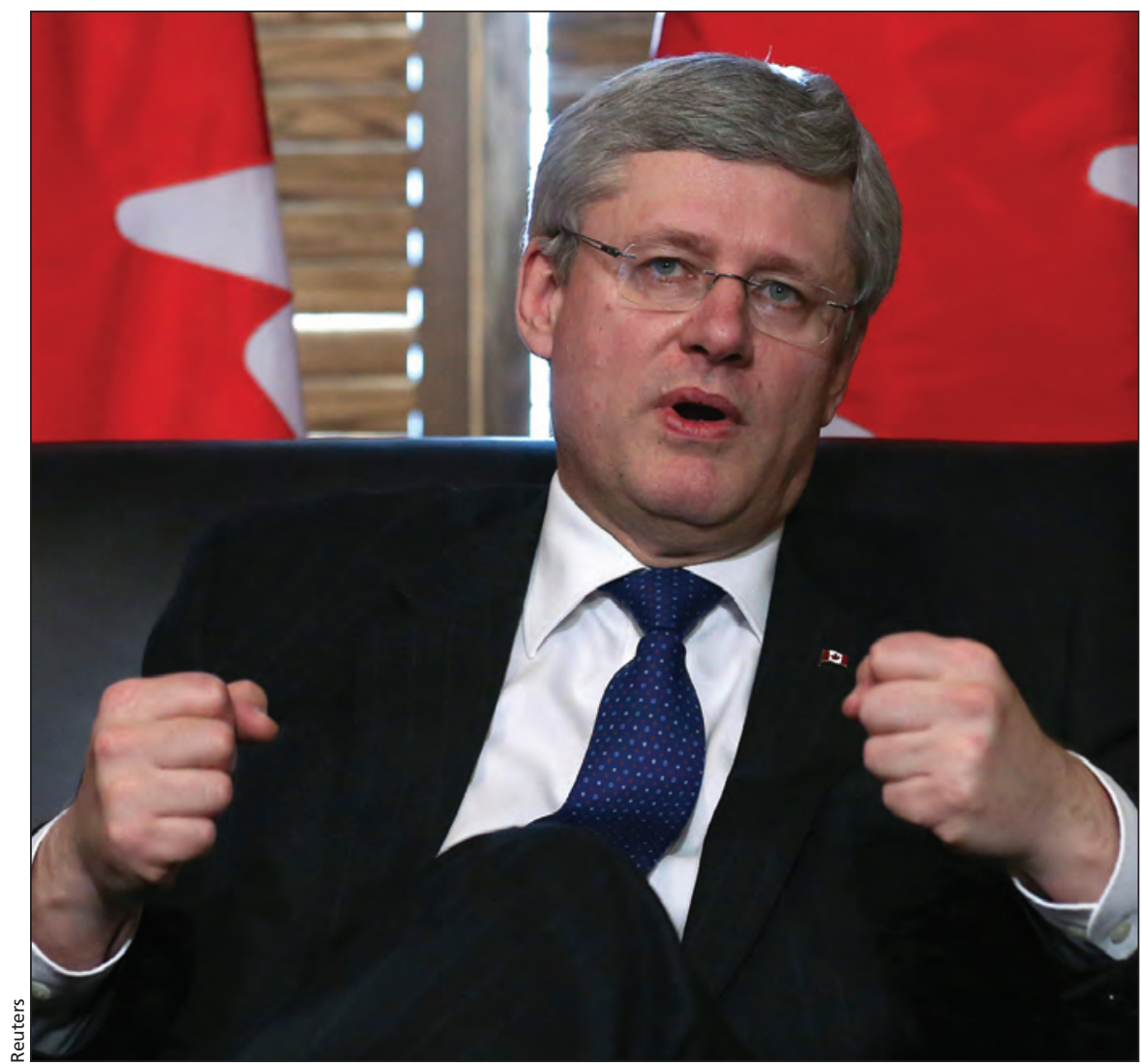

Reductions in health transfers under Prime Minister Stephen Harper's Conservative government mean that provinces and territories will likely receive $\$ 36$ billion less over the next 10 years.

Howe Institute, a nonpartisan think tank, argue that the transfer is "reasonably generous." The previous $6 \%$ escalator was "quite high," he said, and yet "it's very hard to say whether those transfers were able to bring about improved outcomes."

The increased financial load will encourage provinces to be more accountable, said Jason Clemens, executive vice president of the Fraser Institute, a conservative public-policy think tank. "If the provinces spent less time squabbling about getting money from the federal government and more time looking at reforms, then we'd all be better off."

\section{Alberta the sole gainer}

In addition to the reduced annual increase in federal health funding, the built-in equalization mechanism of the health transfer, which gave "have not" provinces more money than "have" provinces, is being eliminated by 2014/15. Instead, the provinces will receive money on a per capita basis. According to the Council of the Federation, this means an additional $\$ 16.5$ million annually in cuts that will affect the poorer provinces.

The CD Howe Institute counters that the federal government's separate equalization program is the best method for subsidizing economically disadvantaged provinces, and the inclusion of equalization into the health transfer didn't adapt well to changing economic conditions.

But the new formula doesn't address the reality that the per capita cost of health care varies among provinces. 
Newfoundland and Labrador "has unique geographic, demographic and population health issues that the new funding approach does not take into account," explained Susan Sullivan, the minister of health and community services, in an email.

As a result of the new per capita system, the federal share of health care funding will fluctuate widely across Canada. In Manitoba, the federal share of health costs will decrease from $20 \%$ to $11 \%$, while in Alberta, the feds will increase its share from $15 \%$ to $20 \%$.

The funding variability across the country undermines the provinces' ability to adhere to the Canada Health Act, said Michael McBane, National Coordinator of the Canadian Health Coalition, an advocacy group aimed at preserving medicare. "You can't have a universal social program unless you have the financial means to have poorer regions subsidized or financially supported."

"The sole gainer in this is Alberta," he added. "Almost everybody else loses."

Alberta Health Minister Fred Horne agreed that his province is benefitting, with an extra $\$ 1$ billion in funding this

federal officials to talk and share best practices; and collected national data.

The new federal funding comes with "zero strings attached," explained Busby at the CD Howe Institute. This means that, outside of the principles defined in the Canada Health Act, there will be no national standards around, for example, wait times or patient safety.

"All the momentum, the better progress around wait times, better reporting on common indicators, more accountability, that's all going by the wayside," laments McBane.

Thanks to financial incentives tied to wait times, 9 of 10 provinces reduced wait times for radiation therapy to within 28 days for $90 \%$ of the population.

John G. Abbott, former CEO of the now-defunct health council, said they effectively highlighted the positives and negatives in the health system's performance at a national level and recommended policy changes. "We felt it should have continued. Most countries have some kind of similar body ... that really acts as a public accountability agency."

Alberta's health minister Horne added that the council "played a useful role in facilitating discussion among

\section{"The sole gainer in this is Alberta. Almost everybody else loses."}

year. "With the fast-growing population we have, it's welcome news." The province grew by 140000 people last year and Alberta has long lobbied for a funding approach that takes population growth into account.

"At the same time ... I have some empathy for the other provinces that will receive less money."

\section{Health Council of Canada gone}

The cancellation of the Health Accord has affected more than funding, it also means the demise of the Health Council of Canada, which was established with the 2004 launch of the Health Accord. The council set national standards on indicators such as wait times and access to home care; provided a forum for provincial, territorial and much happens. "There's no follow through."

\section{More privatization expected}

In anticipation of reduced federal funds, provincial health ministers are already beginning to cut back and to privatize aspects of health care delivery, Silnicki said. New Brunswick privatized hospital laundry services late last year, for example. And Newfoundland and Labrador's Eastern Health eliminated the equivalent of 550 full-time health care jobs.

Jodee Mason, spokesperson for Manitoba Minister of Health Erin Selby, is unequivocal in her view that the quality of health care in her province will suffer as a result of the federal funding cuts. "It will put at risk the progress we have made at reducing wait times and improving access to see a doctor," she wrote in an email.

However, others think Ottawa hasn't gone far enough. Because the federal government has "not clarified the Canada Health Act," the Fraser Institute thinks the provinces will remain tied to public health care. Clemens would have liked to see the federal government do away with the public administration requirement of the act. He claims health systems that allow private health care perform better, and points as evidence to Switzerland and Germany.

The federal government has "removed the strings on the funding side," he said. "I don't think they've done the equivalent on the regulatory side."

Silnicki disagrees with Clemens' analysis: "Every study has borne out that the most cost-efficient way to deliver health care is through a singlepayer system."

A greater provincial responsibility for funding can't encourage efficiencies, she said, especially when the federal government has just downloaded much of its health care responsibilities for refugees, the RCMP and veterans to the provinces.

"This is like asking a drowning person to drown more efficiently while [the federal government] stands on shore holding the lifesaver," she said. — Wendy Glauser, Toronto, Ont.

CMAJ 2014. DOI:10.1503/cmaj.109-4774 